\title{
INTEGRATION SOFTWARE FOR A DISTRIBUTED GROUP OF MOBILE SERVICE ROBOTS
}

\author{
Pryanitchnikov Valentin, Yuri Kolesov, \\ Radomir Tarasov \& Plotnikov Aleksey
}
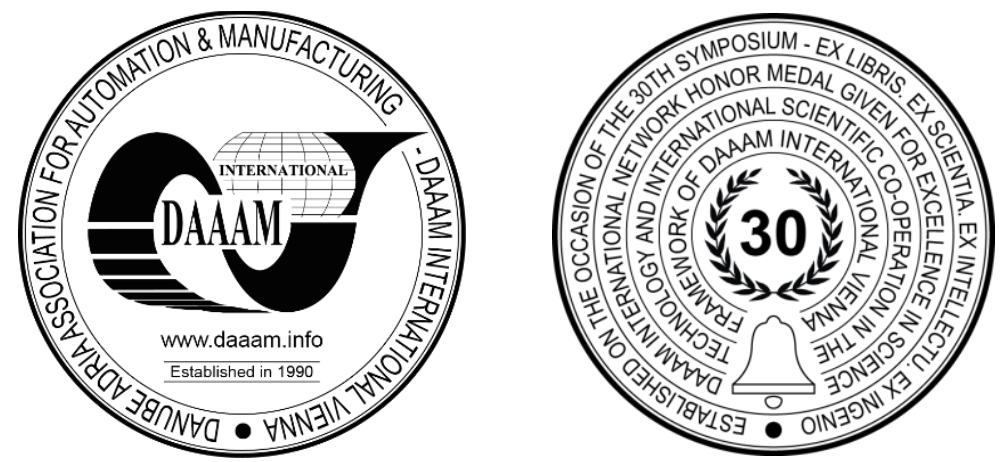

This Publication has to be referred as: Pryanichnikov, V[alentin]; Kolesov, Y[uriy]; Tarasov, R[adomir] \& Plotnikov, A[leksey] (2021). Integration Software for a Distributed Group of Mobile Service Robots, Proceedings of the 32nd DAAAM International Symposium, pp.0311-0315, B. Katalinic (Ed.), Published by DAAAM International, ISBN 978 3-902734-33-4, ISSN 1726-9679, Vienna, Austria

DOI: $10.2507 / 32$ nd.daaam.proceedings.045

\begin{abstract}
This article describes the study of the problems of testing and integration of the group of mobile service robots (Amur307 type) hardware and software complex using the virtualization support library. The architecture of the software solution and its features, that simplify integration testing and speed up debugging of compilation and reliability errors are described. An approach to emulation of hardware, sensors and electric driver of robots with manipulators specific to this software and hardware complex is also outlined, which allows creating a complete virtual analogue of it and speeding up software development (especially in terms of routing a robotic complex) using unit tests.
\end{abstract}

Keywords: integration software; service mobile robots; emulation and testing of hardware and software; based on microprocessors and on-board computers.

\section{Introduction}

Currently, one of the most successful approaches to software development is continuous integration. The software must be ready at any time for launch and execution, so that execution errors do not occur at any arbitrary time [15]. This approach also justifies itself in the development of client software for the Amur-307 robotic complex[1, 2]. In particular, the developed software can be used for the entire spectrum of robotic systems, including underwater ones [17-22], providing better results compared, for example, with work [23].

When developing software in a team, it is necessary to conduct testing at various levels of abstraction: unit testing, integration testing and user interface testing. However, when the program code interacts with various robot equipment, there are moments, that add the need to conduct additional testing using physical equipment [16]. Hardware virtualization is often used to speed up full-featured testing and its automation, which allows not using physical hardware [6]. It is this method, that we have relied on in this work.

\section{Applied software for development and integration}

When developing client software for the Amur-307 robot, the following structure of applied technologies was formed (Fig.1.): 


\section{AmurClient workflow}

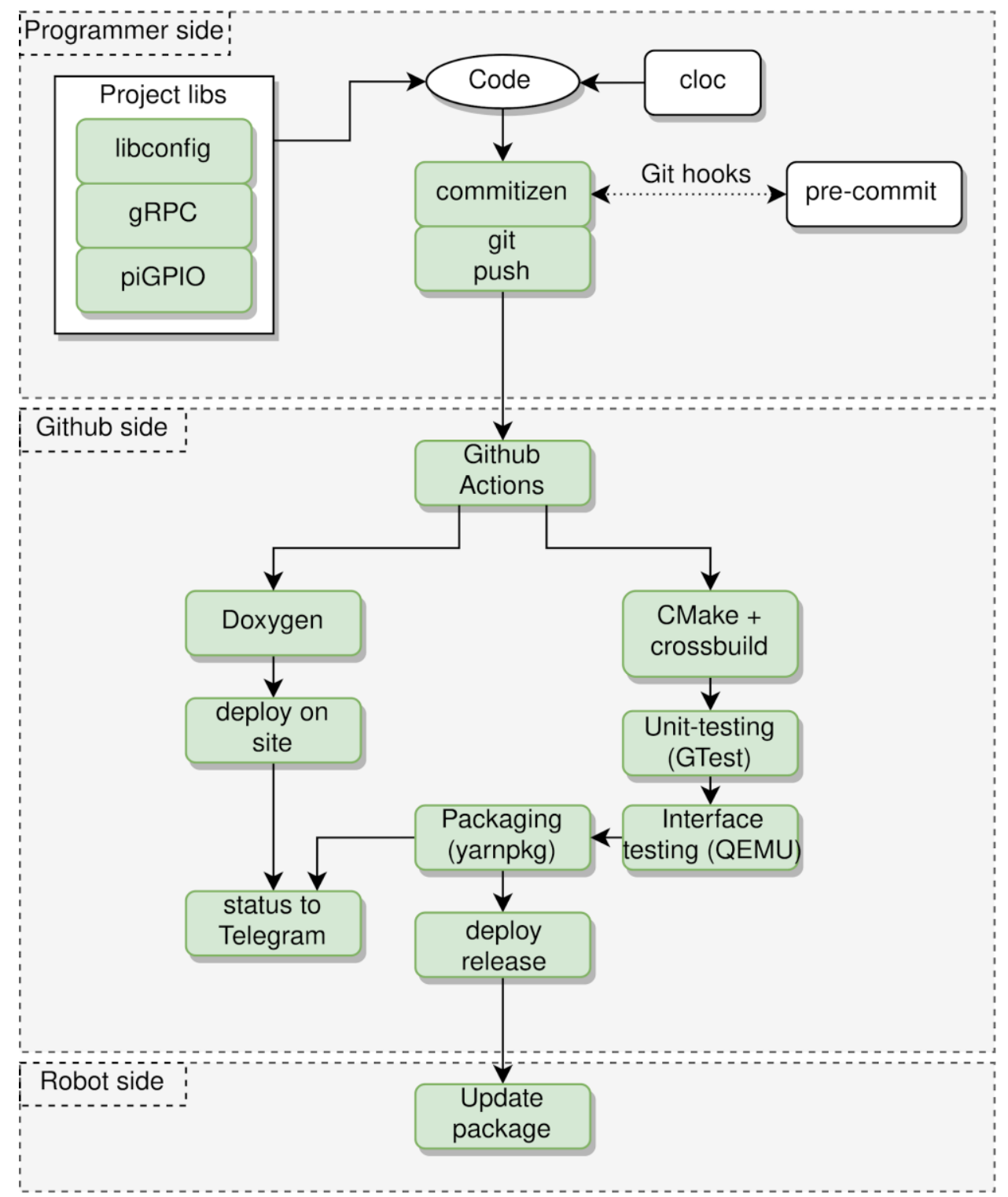

Fig. 1. The structure of applied technologies in the life cycle of client software.

The proposed architecture for testing and debugging client software allows, after making edits to the source codes, to automatically assemble and test software for the Rapsberry Pi platform without resorting to manual testing on a real microcomputer. Also, due to the need for fast and convenient work with the program code, technologies of continuous integration and continuous testing in the repository were used.

For the functioning of the client software, the need for the use of specialized libraries was identified, which would allow to root the development, simplify the testing of system modules, as well as reduce the load on the processor and network [5]. After comparative tests, the following were selected:

1. Network framework gRPC + Protobuf serialize library. This framework was needed for convenient and fast serialization of data into binary format, to reduce the transmitted data and increase the speed of exchange in comparison with the REST API. Also, this framework made it possible to maintain backward compatibility with older versions of microservices, which in turn made it possible to simply change the structures of the transmitted data.

2. piGPIO library. This library provides software for working with peripheral equipment of the Raspberry Pi microcomputer. For this microcomputer, there are several programs for working with GPIO ports, the most popular are WiringPi and piGPIO. WiringPi - at the moment the library is not supported and does not have the necessary DMA modulation to increase the number of PWM signals. At the moment, piGPIO is most often used, due to its functionality and speed of operation. For these reasons, this particular library was chosen.

3. Library libconfig. This library is used to work with configuration files. Its main advantage is cross-platform and entry into the POSIX standard. The configuration file format is readable, and the markup language itself has good functionality. 


\section{Applied technologies of continuous integration and deployment of the project.}

For representativeness, versioning and unification of commits, a separate commitizen program is used. This program significantly saves time when accepting a request to add code to the repository, when viewing the commit history, and also allows you to do some work with the project in semi-automatic mode, such as assigning the current software version and generating a change file. Also, the cloc software package is used to estimate the amount of code, comments and obtain some statistics on the amount of program code. The Git system has a built-in git hooks mechanism, that allows you to perform an action on a specific event. This mechanism is used for additional verification of the commit before it is accepted and access is restricted.

Continuous Integration and Continuous Deployment technologies based on the Github Actions service are used to accelerate development and testing. These technologies allow you to find out the test result, generate documentation and assemble the application package on a third-party server, which in turn greatly reduced the time spent to obtain results. When a new commit is received, two YAML scripts are run on the server, one of which describes the assembly of documentation, and the second describes the assembly and testing of the project itself. The documentation is assembled by Doxygen [13]. Documentation and diagrams are generated based on the client software program code. After the documentation is assembled, build status alerts are sent to the Telegram work chat and if the build was successful, the documentation is updated on the project website.

To compile a project consisting of a large number of code files, it is necessary to use an assembly system that, according to a certain algorithm, will assemble all the files in the correct sequence, and also allow you to run additional precompilation steps. There are several build systems for the $\mathrm{C}++$ language: qmake, make, cmake, autotools. Since there is no pre-installed Qt library in the Raspberry Pi distribution, the qmake build system is not suitable due to the large size of the library, the make system is not cross-platform like autotools. Therefore, the CMake build system is used to build the program, which provides a more user-friendly interface than the Makefile and is cross-platform. Since the final program must be run on an ARM processor, cross-compilation is used, which allows you to compile the project on the server and not load a low-power Raspberry Pi processor. After that, unit testing is required to evaluate the performance of individual modules using the GTest library. After successfully passing the unit tests, it is necessary to run interface testing to make sure that the system as a whole is working properly. For this, a QEMU virtual machine with emulation of Raspberry Pi hardware, including its I/O ports, is used. With the help of a set of programs, an image is created with the recorded Amur-307 [17].

\section{Implementation of a virtual environment for integration testing.}

For virtualization, the following technologies are used to provide interfaces for interaction with virtual hardware: tun/tap, iproute2, iptables, qemu, socat. An example of hardware virtualization can be found in the article [7]. Virtualization in this case uses the full implementation of the TCP/IP stack (this is necessary, among other things, for debugging the server part of the software, which remains outside the scope of this article). When creating a test virtual machine, the topology of the test network is described, since virtualization does not provide automatic access to the local computer network, so it became necessary to add support for the network stack by automatically assigning virtual network interfaces. For this purpose, the TUN/TAP virtual network interface mechanism was chosen [8] since it is already implemented in the Linux OC kernel. To solve the problem of creating, deleting and assigning an ip address, routing, and managing network bridges (the implementation of a virtual network router, also implemented in the OS kernel), the iproute 2 package is used [12]. In this case, this interface was chosen for the speed of development and maximum portability of the code, due to the fact, that ifconfig and route tools similar in purpose are no longer supported in new versions of Linux-based distributions, which in turn will complicate project support.

To connect a virtual machine to a local computer network, the NAT (network address translation) mechanism is used using the iptables package[14]. In this case, the choice of the package is unambiguous: ipfwadm and ipchains are outdated and no longer supported, while the choice of iptables is due to the need to isolate the subnet of the test virtual machine for security and the implementation of an arbitrary network topology.

With the help of a qemu-based virtual machine, it is also launched via the socat interface [9, 10] (which emulates the serial port) we get the result of integration testing, which shows the absence or presence of execution errors when running the Amur-307 software on a virtual machine [3,4]. The result of this launch falls into the pipeline of the sequential integration environment, in our case it is Github Actions.

\section{Mechanism for checking the correctness of source codes and generating executable code.}

Next, debugging of execution errors and new functionality is performed using the integration software described above, if any. The qemu virtual machine allows the use of gpio virtual sensors, which allows us to debug the functionality of the components of the Amur-307 client software on a virtual machine, for example, basic tests of the functionality of various sensors. In addition, it is possible to emulate the work of the robotic complex as a whole, namely, movement along the route, interaction with manipulators and much more, which significantly reduces the debugging time directly on the robot's equipment and allows you to identify machine-independent errors. 
After successful testing, the installation apk package for Raspbian $O S$ is automatically assembled, which is published in the repository releases and also published on the project website.

\section{Conclusion}

As a result of the conducted research, an environment for continuous development with the possibility of testing software on virtual hardware was identified, created and configured. This system allows you to save time developing software for the AMUR-307 robot by eliminating constant testing on real robot hardware, as well as counting the automatic launch of tests with each new commit. As a result of the work of this software package, after the assembly and publication of the release, the package is installed by the user on the robot or updated from the project repository. Thus, the mechanism of continuous development, continuous integration and continuous deployment was implemented.

\section{Acknowledgments}

The work was supported by International Institute of New Education Technologies RSUH and Keldysh IAM Russian academy of sciences in accordance with the common project "Intelligent robotronics"/

\section{References}

[1] Aryskin, A[lexander]; Grigorev, A[leksei]; Khelemendik, R[oman]; Petrakov, M[axim]; Pryanichnikov, V[alentin] \& Tarasov, R[adomir] (2020). System for Monitoring and Control in Industrial Technological Processes, Proceedings of the 31st DAAAM International Symposium, pp.0644-0649, B. Katalinic (Ed.), Published by DAAAM International, ISBN 978-3-902734-29-7, ISSN 1726-9679, Vienna, AustriaDOI: 10.2507/31st.daaam.proceedings.089

[2] Aryskin, A[lexander]; Davydov, O[leg]; Eprikov S[tanislav]; Ksenzenko A[lexander]; Pryanichnikov, V[alentin]; Punenkov O[leg]; Shipovalov E[gor]; Solovyova M[ariia]; Stepanova D[aria]; Tarasov R[adomir] \& Tikhomirov A[lexey](2020). Robotariums implementations witn the Elements of Artificial Intelligence Control, Proceedings of the 31st DAAAM International Symposium, pp.0973-0985, B. Katalinic (Ed.), Published by DAAAM International, ISBN 978-3-902734-29-7, ISSN 1726-9679, Vienna, AustriaDOI: 10.2507/31st.daaam.proceedings.1351 (P. 3)

[3] Aryskin, A[lexander]; Bogdanovich, A[lena]; Davydov, O[leg]; Grigoriev, A[leksey]; Khelemendik, R[oman]; Kharin, K[onstantin]; Kuvshinov, S[ergey]; Petrakov, M[aksim]; Plotnikov A[leksey], Pryanichnikov, V[alentin]; \& Tarasov R[adomir] (2019). Control algorithms for service and industrial transport robots, Proceedings of the 30th DAAAM International Symposium, pp.1166-1173, B. Katalinic (Ed.), Published by DAAAM International, ISBN 978-3-902734-22-8, ISSN 1726-9679, Vienna, Austria. DOI: 10.2507/30th.daaam.proceedings.164

[4] Aryskin, A[leksander] A[.]; Bogdanovich, A[lena]; Davydov, O[leg]; Khelemendik, R[oman]; Petrakov,M[axim] \& Pryanichnikov, V[alentin] (2019). Control and Interaction Algorithms for Industrial and Service Robots, Chapter 33 in DAAAM International Scientific Book 2019, pp.377-384, B. Katalinic (Ed.), Published by DAAAM International, ISBN 978-3-902734-24-2, ISSN 1726-9687, Vienna, AustriaDOI: 10.2507/daaam.scibook.2019.33

[5] R.B. Tarasov, O.I. Davydov, V.E. Pryanichnikov, M.D. Solovyova, A.N. Tikhomirov, E.A. Shapovalov, S.R. Epikov // Software-Control Shell for Service Robots With Parallel Computing. Extreme robotics. // Collection of abstracts of the 31st International Scientific and Technical Conference "Extreme Robotics". - St. Petersburg: CPI LLC "Polytechnic-print", 2020. - 86 p., pp.41-42. ISBN 978-5-85875-602-6.

[6] V.E. Pryanichnikov, E.A. Shapovalov, R.B. Tarasov // Intellectual Support of Logistics Missions in Medical Institutions With Mobile Service Robots AMUR-307. Extreme robotics. // Collection of abstracts of the 31st International Scientific and Technical Conference "Extreme Robotics". - Saint Petersburg: CPI LLC "Polytechnic-print", 2020. - 86 p., p.73. ISBN 978-5-85875-602-6.

[7] Simple, Painless Application Testing on Virtualized Hardware - Star Lab Software. Available at: https://www.starlab.io/blog/simple-painless-application-testing-on-virtualized-hardwarenbsp (Accessed 20 October 2011).

[8] Documentation/Networking - QEMU. Available at: https://wiki.qemu.org/Documentation/Networking\#Tap (Accessed 20 October 2011).

[9] Features/ChardevFlowControl - QEMU. Available at: https://wiki.qemu.org/Features/ChardevFlowControl (Accessed 20 October 2011).

[10] Getting started with socat, a multipurpose relay tool for Linux. Available at: https://www.redhat.com/sysadmin/getting-started-socat (Accessed 20 October 2011).

[11] Ushakov Yu.A., Polezhaev P.N., Shukhman A.E. Creation of a multiservice multipoint VPN network with dynamic auto-tuning. // Bulletin of Orenburg State University. - 2015. - No. 9. - pp. 170-178.

[12] M. Shahin, M. Ali Babar, and L. Zhu, _Continuous Integration, Delivery and Deployment: A Systematic Review on Approaches, Tools, Challenges and Practices”, IEEE Access, 2017. https://arxiv.org/pdf/1703.07019.pdf 
[13] Doxygen, a documentation generator mainly for C++. Available at: https://starkovden.github.io/Doxygen.html (Accessed 20 October 2011).

[14] Mathematical Models and Software Protection Tools for Distributed Computer Systems: Galatenko A.V. abstract of the dissertation for the degree of candidate of Physical and Mathematical Sciences / Institute of System Programming. Moscow, 2004

[15] Davydov D.V., Eprikov S.R., Kirsanov K.B., Pryanichnikov V.E. (2017). Service Robots Integrating Software and Remote Reprogramming, Proceedings of the 28th DAAAM International Symposium, pp.1234-1240, B. Katalinic (Ed.), Published by DAAAM International, ISBN 978-3-902734-11-2, ISSN 1726-9679, Vienna, Austria, DOI: 10.2507/28th.daaam.proceedings.172.

[16] Pryanichnikov V. E. Artificial intelligence and software and hardware robotic systems. Information-measuring and control systems. - 2018. - Vol. 16, No. 12. - Pp. 3-11, ISSN 2070-0814.

[17] Aryskin, A[lexander]; Davydov, O[leg]; Eprikov S[tanislav]; Ksenzenko A[lexander]; Pryanichnikov, V[alentin]; Punenkov O[leg]; Shipovalov E[gor]; Solovyova M[ariia]; Stepanova D[aria]; Tarasov R[adomir] \& Tikhomirov A[lexey] (2020). Robotariums implementations witn the Elements of Artificial Intelligence Control, Proceedings of the 31st DAAAM International Symposium, pp.0973-0985, B. Katalinic (Ed.), Published by DAAAM International, ISBN 978-3-902734-29-7, ISSN 1726-9679, Vienna, Austria DOI: 10.2507/31st.daaam.proceedings.135

[18] V.V. Arykantsev, A. A. Ariskin, O.O. Belyaev, A.Ya. Ksenzenko, E.A.Prysev, V.E. Pryanichnikov, V.V. Chernyshev, S.R.Eprikov. Supervisory control of underwater walking apparatus, Extreme robotics and conversion trends. Collection of abstracts of the international scientific and technical conference, 2018, St.Petersburg, p. 203.

[19] A.Y. Ksenzenko, Yu.S. Marzanov, E.A. Prysev, V.E. Pryanichnikov, V.V. Chernyshev, Prototyping of contactless data exchange and power supply of underwater satellite robots with a base station walking on the bottom, Extreme robotics. Collection of abstracts of the international scientific and technical conference, 2017, St. Petersburg, p. 268.

[20] Bielich T., Ksenzenko A. Ya., Kirsanov K. B., Pryanichnikov V. E. Increasing the time of continuous operation of the underwater inspection robotic complex. Information-measuring and control systems. 2015, No. 7, pp. 51-56, ISSN 2070-0814.

[21] Ksenzenko A.Y, Prysev E.A., Pryanichnikov V.E., Chernyshev V.V., (2017). Intelligent Robotronics: Design the Contactlees Charger and Contactless Data transfer between underwater Robot-Satellits and Underwater 6-legged Vehicle. Proceedings of the 28 th DAAAM International Symposium on Intelligent Manufacturing and Automation, pp. 1197-1201, B. Katalinic (Ed), Published by DAAAD International, ISBN 978-3-902734-08-2, ISSN 1726-9679, Vienna, Austria, DOI: 10.2507/28th.daaam.proceedings.166.

[22] V.V. Chernyshev, V.E. Pryanichnikov, V.V. Arykantsev, I.P. Vershinina, Ya.V. Kalinin, "Research of the walking type of movement in underwater conditions", OCEANS 2019 - Marseille, IEEE, Marseille, France, 2019, pp. 1-6, https://doi.org/10.1109/OCEANSE.2019.8867233.

[23] S.Y. Yoo, B.H. Jun, H. Shim, "Design of Static Gait Algorithm for Hexapod Subsea Walking Robot: Crabster", Transactions of the Korean Society of Mechanical Engineers A. Vol.38, 2014, pp. 989-997, 10.3795/KSMEA.2014.38.9.989. 